\title{
Diagnostic Classifications and Resource Utilization of Decedents Served by the Department of Veterans Affairs
}

\author{
SONIA A. DUFFY, Ph.D., R.N., ${ }^{1,2}$ LAUREL A. COPELAND, Ph.D., ${ }^{3}$ \\ FAITH P. HOPP, Ph.D., M.S.W., ${ }^{1,4,6}$ and ROBERT J. ZALENSKI, M.D. ${ }^{5,6}$
}

\begin{abstract}
Background: Given the volume and cost of inpatient care during the last year of life, there is a critical need to identify patterns of dying as a means of planning end-of-life care services, especially for the growing number of older persons who receive services from the Veterans Health Administration (VHA).

Methods: A retrospective computerized record review was conducted of $20,933 \mathrm{VHA}$ patients who died as inpatients between October 1, 2001 and September 30, 2002. Diagnoses were aggregated into one of five classification patterns of death and analyzed in terms of health care resource utilization (mean number of inpatient days and cumulative outpatient visits in the year preceding the patient's death).

Results: Cancer deaths were the most common (30.4\%) followed by end-stage renal disease (ESRD) (23.2\%), cardiopulmonary failure $(21.4 \%)$, frailty $(\mathbf{1 1 . 6 \%})$, “other" diagnoses $(\mathbf{7 . 3 \%})$, and sudden deaths $(6.1 \%)$. Those with ESRD were more likely to be male and nonwhite $(p<0.05)$ and those with frailty were more likely to be older and married $(p<0.05)$. Controlling for demographic variables, those with frailty had the highest number of inpatient days while those with ESRD had the highest number of outpatient visits. Nonmarried status was associated with more inpatient days, especially among younger decedents.

Conclusion: As a recognized leader in end-of-life care, the VHA can play a unique role in the development of specific interventions that address the diverse needs of persons with different dying trajectories identified through this research.
\end{abstract}

\section{INTRODUCTION}

$\mathbf{T}$ The Veterans Health Administration (VHA), among the largest regionalized health care systems in the United States, ${ }^{1}$ is particularly challenged by the need to provide end-of-life care for the growing number of older veterans. Thirty-seven percent of veterans are over age 64 compared only 13\% of the general population, ${ }^{2,3}$ and veterans account for $28 \%$ of all deaths in the United States annually. ${ }^{4}$ Approximately 1800 of $25,000,000$ veterans die daily (approximately 675,000 per year) and this number increases yearly. ${ }^{5}$

Approximately $15 \%$ of veterans have enrolled in health care services with the VHA. ${ }^{6}$ Approximately $35 \%$ of veterans die in the hospital compared to $17 \%$ of Medicare beneficiaries, indicating that veterans re-

\footnotetext{
${ }^{1}$ VA Center for Clinical Management Research, Health Services Research and Development, Ann Arbor, Michigan.

${ }^{2}$ Nursing, Otolaryngology, Psychiatry, University of Michigan, Ann Arbor, Michigan.

${ }^{3}$ Department of Veterans Affairs, South Texas Veterans Health Care System VERDICT HSR \& D, San Antonio, Texas.

${ }^{4}$ Wayne State University School of Social Work, Detroit, Michigan.

${ }_{5}^{5}$ Department of Emergency Medicine, School of Medicine Center to Advance Palliative-Care Excellence, Wayne State University, Detroit, Michigan.

${ }^{6}$ Center to Advance Palliative Care Excellence, Wayne State University, Detroit, Michigan.
} 
ceive a higher proportion of hospital-based terminal care services compared to Medicare recipients. ${ }^{4}$ Annual direct costs of care for VHA patients in the last year of life totaled approximately $\$ 1,172,237,000$, representing $10 \%$ of the clinical budget spent for a group that comprises less than $1.5 \%$ of the VHA enrolled population (J.L. Hallenbeck JL, J. Breckenridge, unpublished data).

Glaser and Strauss ${ }^{7}$ were the first to discuss patterns of dying, which were defined by duration, change of function over time, and expectation of death, and suggested that these patterns had important implications for service delivery. Further research based on an analysis of Medicare decedents found frailty to be the predominant pattern $(47 \%)$ followed by cancer $(22 \%)$, cardiopulmonary failure $(16 \%)$, sudden death $(7 \%)$, and other $(8 \%) .{ }^{8,9}$ These five groups have been found to differ with respect to demographic characteristics and in terms of use and expenditures for inpatient and outpatient care. ${ }^{9}$ However, the VHA population is different from the Medicare population in terms of the greater proportion of males, the preponderance of medical, mental health-, and substance abuse-related comorbidities, and a lower level of financial resources, suggesting the need for further examination of dying trajectories among this population. Hence, the purpose of this study was to classify inpatient decedents in the VHA in terms of previously established dying trajectories and to compare VHA dying trajectories in terms of demographic characteristics and patterns of inpatient and outpatient service use in the year prior to death.

\section{METHODS}

\section{Design}

A retrospective record review of computerized hospital records during the last year of life was used to classify and analyze dying patterns. The major groups of decedents (end-stage renal disease [ESRD], sudden death, cancer, cardiopulmonary failure, frailty, and "other") were compared in terms of demographic characteristics and inpatient and outpatient service use during the year prior to death. Human studies approval was received from the VHA Ann Arbor Healthcare System.

\section{Sample}

VHA decedents were included in the study if they died between October 1, 2001 and September 30, 2002 in a VHA hospital or VHA extended care facility and were over age 65 at the time of their death. Approximately three quarters of all VHA deaths during this time period occurred among persons aged 65 or older. Inpatient records from the centralized VHA Austin Automation Center (AAC) databases yielded a sample of 20,933 patients. These databases included the main VHA hospital and extended care facility files from fiscal years 2001 and 2002, the corresponding bed-section files (a bed-section is like a ward and reflects the treating clinician's specialty), and the outpatient events files from the same years. Together these files permitted us to assemble data 12 months from date of death. The files contain transmitted information extracted from patients' electronic medical charts according to a nationally standardized protocol and were identified by a scrambled patient identifier unique to each patient. All patient care provided by VHA is documented and missing data on visits and stays is extremely rare.

\section{Procedure}

Similar to other studies, $, 9,10$ disease trajectories were classified in the following hierarchy: (1) ESRD, (2) sudden deaths, (3) cancer deaths, (4) cardiopulmonary failure deaths, (5) frailty deaths, and (6) other. All inpatient diagnoses recorded throughout the last year of life in the bed-section files were examined, including principal admission diagnoses, primary diagnoses (explanation for most days of stay for the overall stay), and secondary diagnoses. ICD-9 codes associated with the diagnoses are shown in Table 1. Death certificates, which have been shown to be highly unreliable for many causes of death, ${ }^{10}$ were not examined. Among dying classifications, ESRD (1) is of interest to the VHA, because a substantial number of veterans are treated for this condition and the disease requires substantial resources to manage. Therefore, unlike previous studies where ESRD was excluded, this study examined ESRD as a separate and distinct category. The sudden death category (2) was defined by age younger than 80 years of age, no more than 2 inpatient days in the last year of life, and ineligibility for the ESRD group. The cancer category (3) was defined by cancer diagnoses in the last year of life and ineligibility for the ESRD or sudden death groups. The cardiopulmonary failure category (4) was defined by diagnosis of cardiopulmonary failure or chronic obstructive pulmonary disease (COPD) and ineligibility for any of the three previous categories. The frailty category (5) was characterized by diagnosis for dementia (including Alzheimer's and Pick's disease), delirium, Parkinson's disease, stroke, hip fracture, pneumonia, incontinence, dehydration, leg cellulitis, or syncope. In addition, frailty patients could not have met criteria for 
Table 1. Demographics and Diagnostic Classification among VHa Inpatient DECEDENTS $(n=20,933)$

\begin{tabular}{lcc}
\hline Characteristic & $\mathrm{n}$ & Value \\
\hline & & $\begin{array}{c}\text { Mean/median } \\
\text { (SD: Range) } \\
77.8 / 77.9\end{array}$ \\
Age & 20,933 & $(6.6: 65-108)$ \\
Annual income & 20,845 & $\$ 16,457 / \$ 11,776$ \\
& & $(\$ 20,448: \$ 0-250,000)$ \\
& & \\
Gender-Male & & Percentage \\
Race-White & 20,401 & $97.5 \%$ \\
Black & 15,230 & $77.4 \%$ \\
Other & 3234 & $16.4 \%$ \\
Marital status-Married & 1218 & $6.2 \%$ \\
Census region & 10,415 & $50.1 \%$ \\
Northeast & & $17.8 \%$ \\
South & 3720 & $43.5 \%$ \\
West & 9097 & $19.1 \%$ \\
Midwest & 3992 & $19.7 \%$ \\
Diagnostic classification & 4124 & \\
(1) End-stage renal disease & & $23.2 \%$ \\
(2) Sudden death & 4851 & $6.1 \%$ \\
(3) Cancer & 1279 & $30.4 \%$ \\
(4) Cardiopulmonary failure & $21.4 \%$ \\
(5) Frail & 6369 & $11.6 \%$ \\
(6) Other & 4478 & $7.3 \%$ \\
\hline
\end{tabular}

aThe cancer category included ICD-9 codes 140-209 excluding 173 (nonmelanoma skin cancer).

b The cardiopulmonary failure category included CHF diagnoses (ICD-9 codes 398.91, 402.01, 402.11, 402.91, 404.01, 404.03, 404.11, 404.13, 404.91, 404.93, and 428) and COPD diagnoses (ICD-9 codes 490, 491, 492, 494, 496, and 493.2x).

'The frailty category was characterized by diagnosis for one of the following: dementia (including Zlzheimer's and Pick's disease; ICD-9 codes 290, 291.2, 292.82, 294.1, 331), delirium (291.0, 293.0, 293.1, 292.81), Parkinson's (332.0), stroke (430-436), hip fracture (820, 733.14), pneumonia $(480-482,485,486)$, incontinence $(625.6,788.3)$, dehydration (276.5), leg cellulitis (682.6), or syncope (780.2)

$\mathrm{SD}$, standard deviation; $\mathrm{CHF}$, congestive heart failure; COPD, chronic obstructive pulmonary disease.

any of the four previous categories. The final category (6) comprised decedents not already categorized into one of the previous five groups. Patients in this group had diagnoses of diabetes, non heart failure-related heart disease such as myocardial infarction or coronary artery disease,, vascular disease, stroke (if under age 80), cirrhosis of the liver, and acquired immune deficiency syndrome (AIDS).

\section{Measures}

Patients were grouped into one of the dying classifications based on inpatient diagnoses. Other variables included age, race (white versus black versus other nonwhite), gender, marital status (married, widowed, divorced, and never married), interaction of age by marital status, annual household income, and Census region (Northeast, Midwest, South, and West). The number of inpatient days and cumulative outpatient visits (including substance abuse treatment, other psychiatric, emergency department, and medical outpatient visits) were calculated by summing across the 365 days preceding death.

\section{Data analysis}

Demographic characteristics for each disease classification were examined using means/standard deviations or frequency distributions. Associations between dying trajectories and demographic characteristics were conducted using $\chi^{2}$ tests for categorical demographic variables and analysis of variance (ANOVA) for continuous variables. Linear regression and analysis of covariance (ANCOVA) were used to 
examine differences in health care utilization (inpatient days and outpatient visits) by diagnosis classification, controlling for age at death, gender, race, marital status, interaction of age by marital status, income, and geographic region.

Multivariate regression models were used to compare the number of inpatient days used during each calendar quarter in the year prior to death, analyzed by the six diagnosis classifications and controlling for age at death, gender, race, marital status, interaction of age by marital status, income, and geographic. In multivariable models, reference categories included male gender, white race, married marital status, and Midwest region. For post hoc comparisons of means, Tukey's adjustment for all pair-wise comparisons was used. An $\alpha$ criterion level of 0.05 denoted significance.

\section{RESULTS}

\section{Description of the VHA sample}

Descriptive characteristics for the sample are shown in Table 1. The mean age was 77.8 (standard deviation $[\mathrm{SD}]=6.6$ ) and the median income was $\$ 11,776$. Most were male, approximately half were married, over three quarters were white, and most lived in the South. Patients were distributed across the six classifications as follows: ESRD, 23.2\%; sudden death, $6.1 \%$; cancer, $30.4 \%$; cardiopulmonary failure, $21.4 \%$; frailty, $11.6 \%$; and other, $7.3 \%$. The majority $(61 \%)$ died in VA extended care facilities and $33 \%$ died in VA hospitals, while $6 \%$ had unclear information because they had discharge records with a valid date of death in both types of facilities.

The multivariate sample was reduced by 1421 persons $(6.8 \%)$ due to missing data. Missing data was ob- served for race $(6 \%, n=1251)$, marital status $(0.6 \%$; $n=131)$, and income $(0.4 \% ; n=88) . \chi^{2}$ analysis revealed that women were more likely to have missing data on race and marital status, persons never married were more likely to have missing data on race, and persons who were either divorced, widowed, or African American were more likely to have missing data on income. In addition, those missing data on race were more likely to also have missing data on marital status. Although some loss of representation did occur in our multivariable analysis with respect to VHA inpatient decedents, the small proportion of missing data suggests that bias from this source was likely negligible.

\section{Demographic differences among the six diagnostic classifications in the VHA}

Demographic differences among the diagnostic classification groups in the VHA sample are shown in Table 2. Frailty patients were the oldest decedents followed by "other" deaths, cardiopulmonary failure, ESRD, cancer, and sudden deaths. There were small but statistically significant gender differences with the ESRD group having the highest proportion of male decedents followed by cardiopulmonary failure, sudden death, frailty, cancer, and "other." The largest proportion of nonwhites $(29.7 \%)$ was in the ESRD group and the smallest proportion of nonwhites $(15.7 \%)$ was in the cardiopulmonary failure group. Decedents in the frailty group were most likely to be married $(56.3 \%)$ while those in the cancer group were less likely to be married (47.1\%). Income did not vary significantly by diagnosis classification $(p=0.48)$. There were slight variations by diagnosis classification for region $\left(\chi^{2}=102.6 ; d f=\right.$ $15 ; p<.001)$.

Table 2. Associations among Independent Variables for VHA Inpatient Decedents $(n=20,933)$

\begin{tabular}{|c|c|c|c|c|c|c|}
\hline $\begin{array}{l}\text { Diagnostic } \\
\text { classification }\end{array}$ & $\mathrm{n}$ & $\begin{array}{c}\text { Age (mean) } \\
(\mathrm{F}=200.5 \\
d f=5 \\
20927 \\
\mathrm{p}<0.001)\end{array}$ & $\begin{array}{c}\text { Male }(\%) \\
\left(\chi^{2}=67.9\right. \\
d f=5 \\
\mathrm{p}<0.001)\end{array}$ & $\begin{array}{c}\text { Nonwhite } \\
(\%) \\
\left(\chi^{2}=280.8\right. \\
d f=10 \\
\mathrm{p}<0.001)\end{array}$ & $\begin{array}{c}\text { Married } \\
(\%) \\
\left(\chi^{2}=64.3\right. \\
d f=5 \\
\mathrm{p}<0.001)\end{array}$ & $\begin{array}{c}\text { Annual } \\
\text { household } \\
\text { income } \\
\text { (No } \\
\text { significant } \\
\text { differences) }\end{array}$ \\
\hline (1) End-stage renal disease & 4851 & 77.4 & 98.4 & 29.7 & 51.2 & $\$ 16,638$ \\
\hline (2) Sudden death & 1279 & 74.3 & 97.4 & 18.9 & 50.4 & $\$ 16,277$ \\
\hline (3) Cancer & 6369 & 76.8 & 97.1 & 23.0 & 47.1 & $\$ 16,306$ \\
\hline (4) Cardiopulmonary failure & 4478 & 79.0 & 98.0 & 15.7 & 50.2 & $\$ 16,140$ \\
\hline (5) Frailty & 2423 & 79.8 & 97.2 & 22.4 & 56.3 & $\$ 17,129$ \\
\hline (6) Other & 1533 & 79.1 & 94.9 & 22.6 & 48.5 & $\$ 16,523$ \\
\hline
\end{tabular}

$d f$, degrees of freedom. 


\section{Differences in health care utilization among the} six classifications in the VHA

As shown in Table 3, after adjusting for demographic covariates, the decedent groups differed significantly on hospital days of stay in the last year of life. Patients in the frailty group had the highest adjusted mean inpatient days $($ mean $=56.5)$ followed by the cardiopulmonary failure group (mean $=$ 51.7), ESRD $($ mean $=50.7)$, cancer $($ mean $=49.4)$, and "other" $($ mean $=39.1)$. Because the sudden death group was limited by definition to no more than 2 inpatient days this group had the lowest number of inpatient days (mean $=0.7$ ) as expected. The mean stay for "other" deaths was significantly lower than for ESRD, cancer, cardiopulmonary failure, and frailty. The mean stay for frailty deaths was significantly higher than for ESRD, cancer, and "other" deaths $(p<0.05)$ for all specified pair-wise comparisons.

Several covariates (not shown in the table) were significant. In particular, the interaction of age by marital status on inpatient days was significant with nonmarried persons using more inpatient days than married persons with this effect especially pronounced among younger persons (age by widowed, $\mathrm{B}=-0.35$; $p<0.06$; age by divorced, $\mathrm{B}=-0.42 ; p<0.05$; age by never married, $\mathrm{B}=0.74 ; p<0.01$ ). Compared to those in the Midwest, veterans residing in the Northeast used more inpatient days $(\mathrm{B}=4.64 ; p<0.01)$; there were no significant differences in inpatient days used for those residing in the South and West compared to Midwest. The adjusted mean number of outpatient visits in the year prior to death also varied significantly by decedent groups with all pair-wise comparisons showing significant differences except between the frailty and other decedents. ESRD dece- dents had the highest number of outpatient visits $($ mean $=46.1)$ followed by cancer decedents $($ mean $=$ 40.3 ), cardiopulmonary failure decedents (mean $=$ $35.2)$, frailty decedents (mean $=26.0)$ and "other" decedents $($ mean $=25.4$ ), while those in the sudden death group averaged the least number of outpatient visits $($ mean $=13.9)$.

Several covariates (not shown in Table 3) revealed significant differences among the trajectory groups. In particular, blacks used significantly more outpatient days than whites $(\mathrm{B}=3.66 ; p<0.001)$. Compared to those who lived in the Midwest, those veterans in the Northeast $(\mathrm{B}=2.33) p<0.01)$ and West $(\mathrm{B}=2.43$; $p<0.001$ ) used more outpatient days; there were no differences in outpatient days used between those who lived in the South compared to the Midwest. The interaction between age and marital status was not significant.

Further analysis by region revealed that in the Northeast, compared to whites, blacks $(\mathrm{B}=6.70 ; p<$ $0.001)$ and those of other races $(\mathrm{B}=8.48 ; p<0.05)$ used more outpatient visits. Similarly in the West, blacks $(\mathrm{B}=10.25 ; p<0.001)$ and those of other races $(\mathrm{B}=5.10 ; p<0.05)$ used more outpatient days compared with whites. In the Midwest, compared to whites, blacks $(\mathrm{B}=3.07 ; p<0.05)$ used more outpatient days while the other category was not significant. In the South there were no significant racial differences in the use of outpatient days.

Table 4 displays mean inpatient days used per quarter in the year prior to death for each of the decedent groups. The significance levels for each group compared with "other" deaths shown in the table are based on the significance levels for the regression model coefficients for each group (not shown), compared with the "other deaths" reference category, and controlling for demographic factors and the interaction of age and

Table 3. Decedent Group Mean Differences in Inpatient and Outpatient Days Used per Patient in the Year Prior to Death, Adjusted for Age, Race, Gender, Marital Status, Interaction of Age by Marital Status, Region, and Income $(n=19,512)$

\begin{tabular}{lcc}
\hline Group & $\begin{array}{c}\text { Mean inpatient days per patient } \\
\text { per year prior to death }\end{array}$ & $\begin{array}{c}\text { Mean outpatient visits per patient } \\
\text { per year prior to death }\end{array}$ \\
\hline (1) End-stage renal disease & $\mathrm{F}=41.46 ; d f=19,19492 ; \mathrm{p}<0.001)$ & $(\mathrm{F}=93.25 ; d f=19,19492 ; \mathrm{p}<0.001)$ \\
(2) Sudden death & $50.7^{\mathrm{a}}$ & $46.1^{\mathrm{a}}$ \\
(3) Cancer & $0.2^{\mathrm{a}}$ & $13.9^{\mathrm{a}}$ \\
(4) Cardiopulmonary failure & $49.4^{\mathrm{a}}$ & $40.3^{\mathrm{a}}$ \\
(5) Frailty & $51.7^{\mathrm{a}}$ & $35.2^{\mathrm{a}}$ \\
(6) Other & $56.5^{\mathrm{a}}$ & $26.0^{\mathrm{a}}$ \\
\hline
\end{tabular}

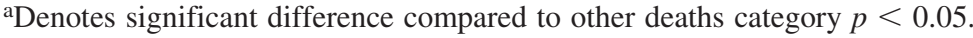

$d f$, degrees of freedom. 
Table 4. Mean Inpatient Days Used for Each Decedent Group for Four Calendar Quarters Prior to Death, Adjusted via Linear Regression for Age, Race, Gender, Marital Status, Interaction of Age $\times$ Marital Status, Income, and Geographical Region $(n=19,512)$

\begin{tabular}{|c|c|c|c|c|}
\hline Group & $\begin{array}{c}\text { Mean inpatient } \\
\text { days } 9-12 \text { months } \\
\text { prior to death } \\
(\mathrm{F}=7026 ; d f=19 \\
19,492 ; \mathrm{p}<0.001)\end{array}$ & $\begin{array}{c}\text { Mean inpatient } \\
\text { days } 6-9 \text { months } \\
\text { prior to death } \\
(\mathrm{F}=11.43 ; d f=19 \\
19,492 ; \mathrm{p}<0.001)\end{array}$ & $\begin{array}{c}\text { Mean inpatient } \\
\text { days 3-6 months } \\
\text { prior to death } \\
(\mathrm{F}=17.01 ; d f=19 \\
19,492 ; \mathrm{p}<0.001)\end{array}$ & $\begin{array}{c}\text { Mean inpatient } \\
\text { days } 0-3 \text { months } \\
\text { prior to death } \\
(\mathrm{F}=74.67 ; d f=19 \\
19,492 ; \mathrm{p}<0.001)\end{array}$ \\
\hline (1) End-stage renal disease & $3.1^{\mathrm{a}}$ & $6.2^{\mathrm{a}}$ & $10.2^{\mathrm{a}}$ & $31.1^{\mathrm{a}}$ \\
\hline (2) Sudden death & $0.0^{\mathrm{a}}$ & $0.0^{\mathrm{a}}$ & $0.0^{\mathrm{a}}$ & $0.8^{\mathrm{a}}$ \\
\hline (3) Cancer & 2.4 & 5.1 & 9.5 & $32.5^{\mathrm{a}}$ \\
\hline (4) Cardiopulmonary failure & $3.2^{\mathrm{a}}$ & $6.7^{\mathrm{a}}$ & $11.2^{\mathrm{a}}$ & $30.5^{\mathrm{a}}$ \\
\hline (5) Frailty & $2.9^{\mathrm{a}}$ & $7.5^{\mathrm{a}}$ & $13.1^{\mathrm{a}}$ & $33.0^{\mathrm{a}}$ \\
\hline (6) Other & 1.9 & 4.1 & 8.0 & 25.1 \\
\hline
\end{tabular}

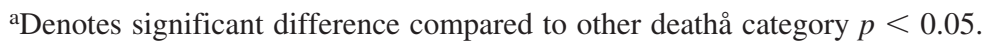

$d f$, degrees of freedom.

marital status. During each of the calendar quarters, the ESRD, cancer, cardiopulmonary, and frailty patients used more inpatient days compared to the "other" deaths category. As expected, when compared to other deaths, sudden death patients used significantly fewer days in each quarter with no hospital days until the last quarter prior to death when only 1.2 days were used. For all diagnostic categories except sudden death, the mean number of days increased steadily each quarter with the greatest number of days used in the last quarter prior to death.

Among sociodemographic variables (not shown in Table 4), none were significant in the 9-12 months prior to death and only Northeast region compared to Midwest $(\mathrm{B}=1.23 ; p<0.01)$ was related to more hospital days in the 6-9 month quarter. In the quarter 3-6 months prior to death, age by widowed $(\mathrm{B}=$ $-0.17 ; p<0.05)$, age by divorced, $(\mathrm{B}=-.14 ; p<$ $0.05)$, age by never married $(\mathrm{B}=-0.26 ; p<0.01)$, and Northeast region compared to Midwest $(\mathrm{B}=1.28$; $p<0.05$ ) were significant. In the final quarter prior to death, these interactions were again significant (age by widowed, $\mathrm{B}=-0.23 ; p<0.01$; age by divorced, $\mathrm{B}=$ $-0.14 ; p<0.09$; age by never married, $\mathrm{B}=-0.42$; $p<0.001$; Northeast region, $\mathrm{B}=1.93 ; p<0.01)$. In both quarters, unmarried persons used more inpatient days than those married especially among younger persons.

\section{DISCUSSION}

The results of this study indicate that with the exception of persons experiencing sudden death, those who die as inpatients have hospital stays of approximately 1 month during the last calendar quarter prior to death with a range from 25.1 days for the "other" death category to 33.0 days for those experiencing frailty deaths. This suggests that those who die as inpatients spend considerable time in inpatient units, which are often oriented around the provision of acute care while neglecting palliative focused services. ${ }^{11}$ Clinicians need to provide good symptom management for these patients, with particular attention to their emotional and spiritual needs, and attend to tasks of closure which includes reconciliation and last expressions of love and good-bye. Hospice workers frequently provide these services to ensure quality of life, and although hospice models should continue to be encouraged, end-of-life services should also be emphasized for persons with a poor prognosis who have a high risk of experiencing death in an inpatient setting.

This study showed that nearly one quarter of VHA inpatient deaths occurred among persons with cardiopulmonary failure. Previous research suggests that despite the high rate of mortality, few persons with cardiopulmonary failure receive appropriate palliative care services. ${ }^{12}$ Good palliative care for cardiopulmonary failure patients must include patient-centered discussions of prognosis, discussion and agreement on the goals of care (from life extension to comfort care only), meticulous symptom care, support for end of life spiritual needs, and tasks of closure. The average days of stay for cancer deaths (49 days) or cardiopulmonary failure (51 days) were lengthy compared to "other" causes, suggesting the potential utility of increased palliative focused attention to persons with these diagnoses. The most common diagnostic classification among VHA patients was cancer $(30.4 \%)$ followed by ESRD (23.2\%) and cardiopulmonary failure (21.4\%). Although not exactly comparable, a similar study conducted among Medicare decedents (34\% of 
whom died in hospitals) found lower proportions of persons with cancer (22\%) and organ failure (16\%). ${ }^{9}$ In contrast, fewer VHA inpatient decedents (11.6\%) were categorized as frail compared to the Medicare sample (47\%). There were similar proportions of VHA and Medicare patients in the diagnosis classifications of sudden death (6.1\% VHA versus $7 \%$ Medicare) and "other" deaths (7.3\% VHA versus $8 \%$ Medicare). These differences are consistent with the recognition that VHA services a patient population that is sicker than the U.S. population at large. ${ }^{13}$ Veterans who use VHA care frequently have higher rates of mental illness, substance abuse, and tobacco addictions than the general population ${ }^{14-18}$ that contribute to lifestyle-related disorders, primarily cancers and cardiopulmonary failure (heart disease and chronic obstructive pulmonary disease).

Half of the veterans had an income below \$11,776 and may lack resources to obtain the care they need. Lack of resources and social support predicts psychological distress, ${ }^{19}$ depression, ${ }^{20-22}$ and hospitalization. ${ }^{23}$ Many low-income people struggle to get quality health care, and need encouragement to engage in greater communication and advocacy on issues related to end-of-life care. ${ }^{24}$ Unlike the Medicare patient population, our sample was mostly male $(97.5 \%)$. Men have been found to be less likely than women to want extensive measures conducted to extend life. ${ }^{25}$ Not surprisingly, therefore, veterans have been found to be more likely to oppose the use of heroic measures to extend life compared with non-veterans and are also less likely to have a proxy or durable power of attorney. ${ }^{26}$ Moreover, previous exposure to traumatic or life-threatening combat situations may influence veterans' end-of-life preferences, issues, and needs.

About $16 \%$ of all veterans are minorities, of whom $13.6 \%$ are African American or Hispanic/Latino, and the number of minority veterans is rapidly increasing. ${ }^{2,27}$ Black and Hispanic/Latino veterans are twice as likely as non-Hispanic white veterans to prefer the VHA to other systems of care. ${ }^{28}$ The large number of non-white persons in our sample $(22.6 \%)$ suggests the need for racially and culturally sensitive care. ${ }^{25,29}$ Prior research has shown that blacks are more likely than others to prefer going to a hospital or nursing home to die. ${ }^{25}$ Of particular importance are findings from this study indicating that blacks and persons in the other race category used more outpatient days than whites during the last year of life. This may be due to the greater proportion of nonwhites in the ESRD group requiring outpatient dialysis and suggests the need to provide culturally sensitive care for the growing number of racial and ethnic minorities in the United States. ${ }^{25}$
The VHA has taken aggressive and commendable steps in increasing access to and provision of palliative care. In 2002, a VHA National Policy Board required all VHA hospitals to have inpatient beds designated for hospice and palliative care, or access to these services in the community, and a policy was enacted in 2003 requiring all VHA hospitals to have a multidisciplinary palliative care team in place. Moreover, the VHA has developed the Hospice-Veteran Partnership Initiative to increase veterans' access to home hospice services by strengthening collaborations between VHA facilities and community hospice providers. Nationwide, nearly two-thirds of inpatient veterans deemed appropriate for advanced care planning have discussed preferences with their clinician. ${ }^{24}$ While the VHA has made progress toward improving end-of-life care, this and other studies have shown that end of life care and preferences can vary by race/ethnicity, ${ }^{30-33}$ gender, ${ }^{34-37}$ and socioeconomic status, ${ }^{38}$ and that the VHA will need to plan for demographic differences within disease categories. For example, this study found that cancer patients were more likely than other trajectory groups to be unmarried. To the extent that unmarried status is a marker for a lack of social support, this finding suggests that veterans with cancer may be particularly in need of more supportive services. The VHA, like other health systems, struggles with a perennial shortage of funds and growing patient demands for end of life care. The patterns of veteran deaths examined in this study may be helpful for VHA and other hospital systems as they plan for the resources needed to provide appropriate care at the end of life.

\section{Limitations of the study}

This study only examined veterans who died as inpatients. Consequently, the findings do not necessarily apply to veterans who die elsewhere. Moreover, some veterans included in this study may have used non-VA outpatient care prior to dying as a patient in a VHA hospital, and so their total use of outpatient care (both VHA and non-VHA care) in the year prior to death may be under-reported. Moreover, although the VHA has established a mechanism to track palliative care activity using ICD-9 code V67 that is available in VHA secondary datasets, to date this code has not been routinely or universally used in the VHA system and, therefore, was not used in this study to draw conclusions about palliative care services in the VHA. Despite these limitations, this study is the first to classify patterns of dying among a large sample $(n=$ 20,933) of end-of-life users of VHA inpatient services. 


\section{CONCLUSION}

VHA inpatient decedents have unique demographic characteristics which impact their health service utilization patterns. Identification of these patterns is useful in preparing patients and family members to face end-of-life issues, development of appropriate hospice, palliative, and community-based approaches, and further specification of appropriate hospice care referral guidelines. Moreover, this information is useful in guiding further research as well as policies for future health care resource allocation.

\section{ACKNOWLEDGMENTS}

This research was partially supported by the Department of Veterans Affairs, Veterans Health Administration, Health Services Research and Development Service. This work was completed with the additional support of the VA Ann Arbor Healthcare System in Ann Arbor, Michigan and the VERDICT Research Program at the South Texas Veterans Health Care System, San Antonio, Texas. Dr. Copeland is funded by the Merit Review Entry Program MRP-05-145 from the VA Health Services Research and Development program. Dr. Hopp is funded by Health Services Research and Development Grant \#CHI-03-007, Evaluation of a Cardiac Nurse Practitioner Palliative Care Program, and by the Hartford Faculty Scholars Program, a venture funded by the John A. Hartford Foundation administered by The Gerontological Society of America. The views expressed in this article are those of the authors and do not necessarily represent the views of the Department of Veterans Affairs, the Hartford Foundation, or the Gerontological Society of America.

\section{REFERENCES}

1. Ashton CM, Petersen NJ, Souchek J, Menke TJ, Pietz K, Yu HJ, Wray NP: Rates of health services utilization and survival in patients with heart failure in the Department of Veterans Affairs medical care system. Am J Med Qual 1999;14:55-63.

2. Department of Veterans Affairs: VetPop 2001, Table 5L: veterans by race/ethnicity, 1990-2030. 2001. http://www. va.gov/vetdata/demographics/vetpop2001/data/5L.xls (Last accessed November 2004).

3. US Census Bureau: Census 2000 Summary File 1. April 1, 2000. http://factfinder.census.gov/servlet/DatasetMainPage Servlet?_lang=en (Last accessed December 10, 2004).

4. Principi AJ, Tobin D, Breckenridge J, Kussman M: Creating \& Expanding Hospice \& Palliative Care Programs in VA. April 16, 2002. http://www.va.gov/oaa/flp/ (Last accessed November 2004).
5. Department of Veterans Affairs: VetPop2001Adj State and National Tables. http://www.va.gov/vetdata/demographics/VP2001adjsn.htm (Last accessed December 10, 2004).

6. Department of Veterans Affairs Hospice and Palliative Care Initiative (VAHPC): The hospice-veteran partnership toolkit. http://www.mywhatever.com/cifwriter/library/77/ 5846.html (Last accessed November 2004).

7. Glaser B, Strauss A: Time for Dying. Chicago: Aldine, 1968.

8. Lynn J: Perspectives on care at the close of life. Serving patients who may die soon and their families: The role of hospice and other services. JAMA 2001;285:925-932.

9. Lunney JR, Lynn J, Hogan C: Profiles of older medicare decedents. J Am Geriatr Soc 2002;50:1108-1112.

10. Smith Sehdev AE, Hutchins GM: Problems with proper completion and accuracy of the cause-of-death statement. Arch Intern Med 2001;161:277-284.

11. Steinhauser KE, Christakis NA, Clipp EC, McNeilly M, Grambow S, Parker J, Tulsky JA: Preparing for the end of life: preferences of patients, families, physicians, and other care providers. J Pain Symptom Manage 2001;22:727-737.

12. Stewart S: Prognosis of patients with heart failure compared with common types of cancer. Heart Fail Monit 2003;3:87-94.

13. Agha Z, Lofgren RP, VanRuiswyk JV, Layde PM: Are patients at Veterans Affairs medical centers sicker? A comparative analysis of health status and medical resource use. Arch Intern Med 2000;160:3252-3257.

14. Duffy SA, Ronis DL, Valenstein M, Fowler KE, Lambert MT, Bishop C, Terrell JE: Depressive symptoms, smoking, alcohol use and quality of life among head and neck cancer patients. Psychosomatics 2007;48:142-148.

15. Klevens RM, Giovino GA, Peddicord JP, Nelson DE, Mowery P, Grummer-Strawn L: The association between veteran status and cigarette-smoking behaviors. Am J Prev Med 1995;11:245-50.

16. McKinney WP, McIntire DD, Carmody TJ, Joseph A: Comparing the smoking behavior of veterans and nonveterans. Public Health Rep 1997;112:212-217; discussion 218.

7. Poirier MF, Canceil O, Bayle F, Millet B, Bourdel MC, Moatti C, Olie JP, Attar-Levy D: Prevalence of smoking in psychiatric patients. Prog Neuropsychopharmacol Biol Psychiatry 2002;26:529-537.

18. Regier DA, Farmer ME, Rae DS, Locke BZ, Keith SJ, Judd LL, Goodwin FK: Comorbidity of mental disorders with alcohol and other drug abuse. Results from the Epidemiologic Catchment Area (ECA) Study. JAMA 1990;264: 2511-2518.

19. Paykel ES: Life events, social support and depression. Acta Psychiatr Scand Suppl 1994;377:50-58.

20. Morris PL, Robinson RG, Raphael B, Bishop D: The relationship between the perception of social support and poststroke depression in hospitalized patients. Psychiatry 1991; 54:306-316.

21. Duer S, Schwenk TL, Coyne JC: Medical and psychosocial correlates of self-reported depressive symptoms in family practice. J Fam Pract 1988;27:609-614.

22. Brown GW, Andrews B, Harris T, Adler Z, Bridge L: Social support, self-esteem and depression. Psychol Med 1986;16:813-831. 
23. Mistry R, Rosansky J, McGuire J, McDermott C, Jarvik L: Social isolation predicts re-hospitalization in a group of older American veterans enrolled in the UPBEAT Program. Unified Psychogeriatric Biopsychosocial Evaluation and Treatment. Int J Geriatr Psychiatry 2001;16: 950-959.

24. Last Acts. Transforming Death in America. Washington, D.C.: Partnership for Caring, Inc., 2002.

25. Duffy SA, Jackson FC, Schim SM, Ronis DL, Fowler KE: Racial/ethnic preferences, sex preferences, and perceived discrimination related to end-of-life care. J Am Geriatr Soc 2006;54:150-157.

26. Duffy SA, Ronis D, Fowler K, Schim SM, Jackson FC: Differences in veterans' and nonveterans' end-of-life preferences: A pilot study. J Palliat Med 2006;9:1099-1105.

27. Department of Veterans Affairs: National Survey of Veterans. Washington, D.C.: US Government Printing Office, 1995.

28. Harada ND, Damron-Rodriguez J, Villa VM, Washington DL, Dhanani S, Shon H, Chattopadhyay M, Fishbein H, Lee M, Makinodan T, Andersen R: Veteran identity and race/ethnicity: Influences on VA outpatient care utilization. Med Care 2002;40:I117-128.

29. Gordon AK: Hospice and minorities: A national study of organizational access and practice. Hosp J 1996;11: 49-70.

30. Eleazer GP, Hornung CA, Egbert CB, Egbert JR, Eng C, Hedgepeth J, McCann R, Strothers H 3rd, Sapir M, Wei M, Wilson M: The relationship between ethnicity and advance directives in a frail older population. $\mathrm{J}$ Am Geriatr Soc 1996;44:938-943.

31. Blackhall L, Murphy S, Frank G, Michel V, Azen S: Ethnicity and attitudes toward patient autonomy. JAMA 1995; 274:820-825.

32. Caralis PV, Davis B, Wright K, Marcial E: The influence of ethnicity and race on attitudes toward advance directives, life-prolonging treatments, and euthanasia. J Clin Ethics 1993;4:155-165.
33. Hornung CA, Eleazer GP, Strothers HS 3rd, Wieland GD, Eng C, McCann R, Sapir M: Ethnicity and decision-makers in a group of frail older people. J Am Geriatr Soc 1998;46:280-286.

34. Wenger NS, Pearson ML, Desmond KA, Harrison ER, Rubenstein LV, Rogers WH, Kahn KL: Epidemiology of do-not-resuscitate orders. Disparity by age, diagnosis, gender, race, and functional impairment. Arch Intern Med 1995;155:2056-2062.

35. Bookwala J, Coppola KM, Fagerlin A, Ditto PH, Danks JH, Smucker WD: Gender differences in older adults' preferences for life-sustaining medical treatments and end-oflife values. Death Stud 2001;25:127-149.

36. Johnson MF, Lin M, Mangalik S, Murphy DJ, Kramer AM: Patients' perceptions of physicians' recommendations for comfort care differ by patient age and gender. J Gen Intern Med 2000;15:248-255.

37. Blackhall LJ, Frank G, Murphy ST, Michel V, Palmer JM, Azen SP: Ethnicity and attitudes towards life sustaining technology. Soc Sci Med 1999;48:1779-1789.

38. Mebane EW, Oman RF, Kroonen LT, Goldstein MK: The influence of physician race, age, and gender on physician attitudes toward advance care directives and preferences for end-of-life decision-making. J Am Geriatr Soc 1999; 47:579-591.

Address reprint requests to: Sonia A. Duffy, Ph.D. VA HSR\&D Center for Clinical Management Research

VA Ann Arbor Healthcare System Department of Veterans Affairs HSR\&D (11H)

P.O. Box 130170

Ann Arbor, MI 48113-0170

E-mail: Sonia.Duffy@va.gov 